Review

\title{
Metal Organic Frameworks Derived Nano Materials for Energy Storage Application
}

\author{
Guoxu Zheng ${ }^{1, *}$, Minghua Chen ${ }^{2}$, Jinghua Yin ${ }^{1, *}$, Hongru Zhang ${ }^{2}$, Xinqi Liang ${ }^{2}$, Jiawei Zhang ${ }^{2}$ \\ ${ }^{1}$ School of Materials Science and Engineering, Harbin University of Science and Technology, Harbin \\ 150080, P. R. China \\ ${ }^{2}$ Key Laboratory of Engineering Dielectric and Applications (Ministry of Education), and School of \\ Applied Science, Harbin University of Science and Technology, Harbin 150080, PR China \\ *E-mail: shandian2008.ok@163.com
}

doi: $10.20964 / 2019.03 .28$

Received: 6 December 2018 / Accepted: 6 January 2019 / Published: 7 February 2019

\begin{abstract}
Metal organic frameworks (MOFs) and derived Nano-materials have attracted much attention due to their various controllable nanostructures with large surface area and high porosity. MOFs are usually used as precursors or template to prepare various derived Nano-materials. This paper reviews the development of typical MOFs derived material design and synthesis progresses when they are used as electrodes material for energy storage such as lithium-ion batteries (LIBs), sodium-ion batteries (SIBs) and super-capacitor (SCs). Porous carbon, metal oxide, carbon matrix hybrid, mixed metal and two dimensional MOFs derived material $(\mathrm{Zn}, \mathrm{Co}, \mathrm{Cu})$ are mainly presented. Besides, the major challenges and perspectives are mentioned in the end of review.
\end{abstract}

Keywords: MOFs, Lithium-ion batteries, Super-capacitors, Sodium-ion batteries

\section{FULL TEXT}

(C) 2019 The Authors. Published by ESG (www.electrochemsci.org). This article is an open access article distributed under the terms and conditions of the Creative Commons Attribution license (http://creativecommons.org/licenses/by/4.0/). 